\title{
New Congress Takes Aim at Maternal Health Inequities
}

Michelle Winokur, DrPH, and the AfPA Governmental Affairs

Team, Alliance for Patient Access (AfPA)

The Alliance for Patient Access (allianceforpatientaccess.org), founded in 2006, is a national network of physicians dedicated to ensuring patient access to approved therapies and appropriate clinical care. AfPA accomplishes this mission by recruiting, training and mobilizing policy-minded physicians to be effective advocates for patient access. AfPA is organized as a non-profit 501(c)(4) corporation and headed by an independent board of directors. Its physician leadership is supported by policy advocacy management and public affairs consultants. In 2012, AfPA established the Institute for Patient Access (IfPA), a related 501(c) (3) non-profit corporation. In keeping with its mission to promote a better understanding of the benefits of the physician-patient relationship in the provision of quality healthcare, IfPA sponsors policy research and educational programming.

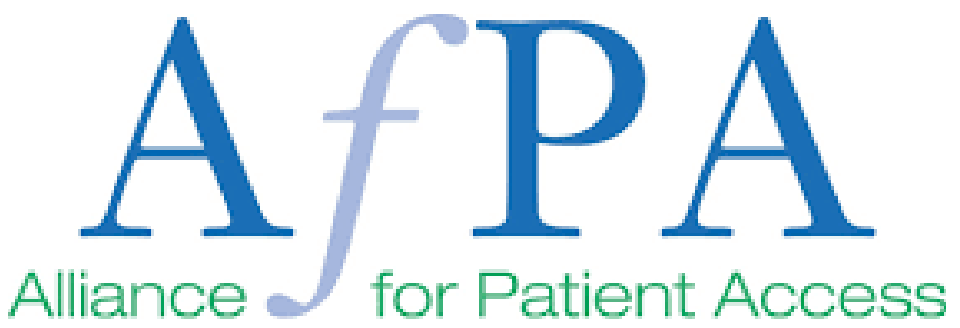

The $117^{\text {th }}$ United States Congress, which first convened in January, is the most racially and ethnically diverse Congress to date. (1) Nearly a quarter of voting members are people of color. More than a quarter are women.(2) It should not come as a surprise then that this Congress quickly proposed multiple bills on health inequities affecting women in underserved and rural communities.

Pregnancy-related mortality is one of those issues. Native American moms are dying at more than twice the rate of their white counterparts. Black moms are three times more likely to die than white moms. (3)

\section{The Black Maternal Health Momnibus Act of 2021}

In February, the Black Maternal Health Caucus of the U.S. House of Representatives introduced the Black Maternal Health Momnibus Act of 2021. (4) The package includes 12 bills that collectively "address every dimension of the maternal health crisis in the United States." Vaccines, social determinants of health, mental health care, and the perinatal workforce are among the topics of individual bills.

More than 190 organizations have declared their support for the legislative Mominibus. Proponents include the Association of Women's Health, Obstetric and Neonatal Nurses, among others.

"These bills align with our agenda of reducing maternal morbidity

\section{"Nearly a quarter of voting members are people of color. More than a quarter are women.(2) It should not come as a surprise then that this Congress quickly proposed multiple bills on health inequities affecting women in underserved and rural communities."}

and mortality, improving the health status of women, addressing racial health disparities and structural and social determinants of health, and resolving health inequities contributing to these issues," declared Cyndy Krening, MS, the association's president.

\section{The Rural Maternal and Obstetric Modernization of Services Act}

Also, in February, Representatives Dan Newhouse (R-WA) and Cindy Axne (D-IA) led another group of lawmakers in refiling the Rural Maternal and Obstetric Modernization of Services Act.(5) The legislation extends support to rural moms, who are experiencing inequitable maternal mortality rates, too.

"Rural areas have a maternal mortality rate that is $38 \%$ higher than urban area," according to a one-pager from the bill's sponsors.(6) It also noted that maternal health care's disappearance in rural America disproportionately affects people of color. (7)

These outcomes are driven, in part, by the shortage of health care providers and the lack of access to labor and delivery hospital services in remote areas. (8) Financial strain has forced many rural hospitals to close their labor and delivery units or shutter their entire facility. This forces expectant and new moms to travel great distances to get quality maternal health care. Ten to $40 \%$ do not keep a postpartum appointment in part because of geographic isolation or limited transportation. (9)

The Rural MOMS Act aims to address these access challenges by expanding existing federal telehealth grant programs to include birth and postpartum services. It will also establish a rural maternal and obstetric care training demonstration to provide maternal care services in rural community-based settings.

The United States posts the highest maternal mortality rates in the developed world. (10) It is even more disturbing that the vast majority of these deaths are preventable. Now, an enthusiastic new Congress appears committed to addressing the drivers of this unfortunate and rising trend. As Representative Alma Adams (D-NC) declared, "Black mamas can't afford to wait."

\section{References}

1. https://www.pewresearch.org/fact-tank/2021/01/28/racial-ethnic-diversity-increases-yet-again-with-the-117thcongress/

2. https://www.pewresearch.org/fact-tank/2021/01/15/a-recordnumber-of-women-are-serving-in-the-117th-congress/

3. https://www.cdc.gov/reproductivehealth/maternal-mortality/ pregnancy-mortality-surveillance-system.htm?CDC AA refVal=https $\% 3 A \% 2 F \% 2 F w w w . c d c . g o v \% 2$ Freproductivehealth\%2Fmaternalinfanthealth\%2Fpregnancy-mortality-s 
urveillance-system.htm

4. https://blackmaternalhealthcaucus-underwood.house.gov/ Momnibus

5. https://newhouse.house.gov/media-center/press-releases/ newhouse-axne-introduce-bill-improve-healthcare-accessoutcomes-new-and

6. https://newhouse.house.gov/sites/newhouse.house.gov/ files/Rural\%20MOMS\%200ne\%20Pager.pdf

7. $\quad$ https://ccf.georgetown.edu/2020/06/12/rural-disparities-racial-disparities-and-maternal-health-crisis-call-out-for-solutions/

8. $\quad$ https://www.pewtrusts.org/en/research-and-analysis/articles/2020/02/25/child-and-maternal-health-in-rural-areaslags-the-nation-highlighting-barriers-to-access

9. https://www.pewtrusts.org/en/research-and-analysis/articles/2020/02/25/child-and-maternal-health-in-rural-areaslags-the-nation-highlighting-barriers-to-access

10. https://www.commonwealthfund.org/publications/issuebriefs/2020/nov/maternal-mortality-maternity-care-uscompared-10-countries\#: : text=Key\%20Findings\%3A\%20 The \%20U.S.\%20has, and $\% 20$ midwives) $\% 2$ 20relative $\% 20$ to\%20births.

Michelle Winokur, DrPH, is the Policy Communications Director for the Alliance for Patient Access.

Disclosures: none

NT
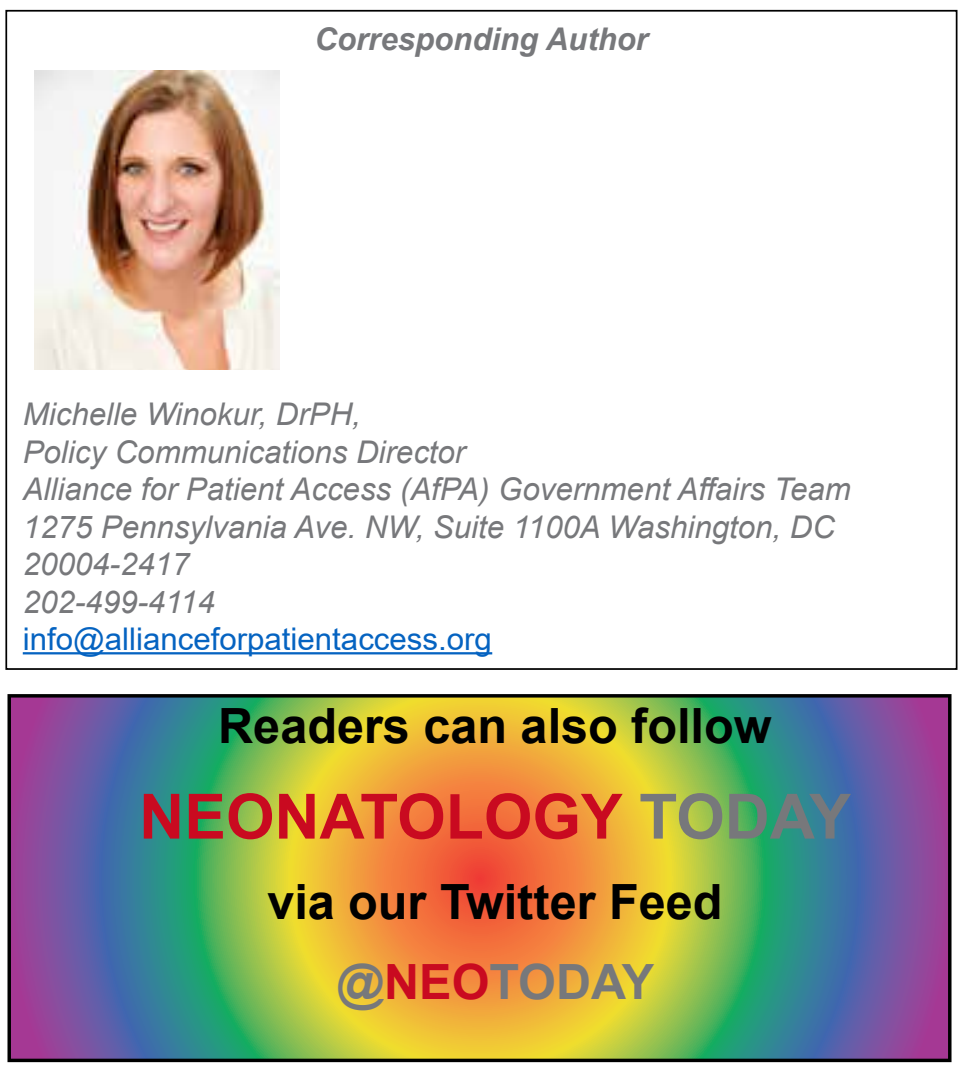

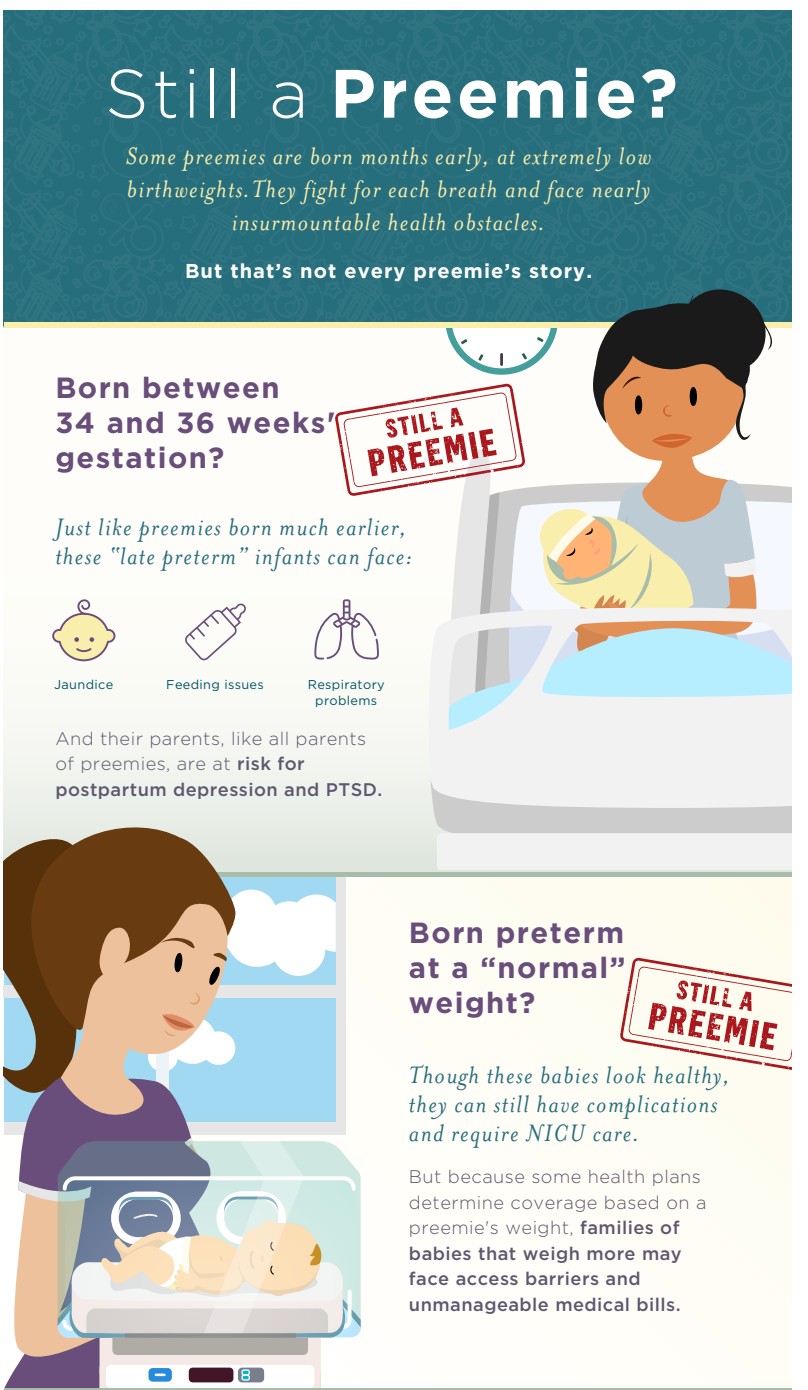

Born preterm but not admitted to the NICU?

Even if preterm babies don't require NICU care, they can still face health challenges.

Those challenges can extend through childhood, adolescence and even into adulthood.
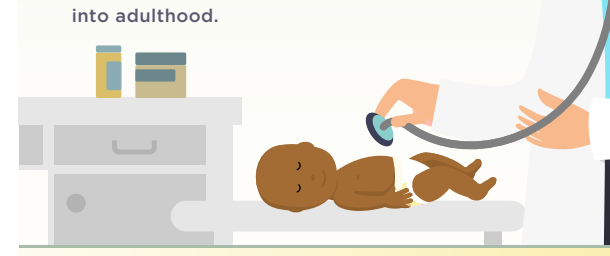
Some Preemies
Will spend week
in in the hospital
- Will have lifelong
우요 Are disadvantaged
䠉 from birth

All Preemies

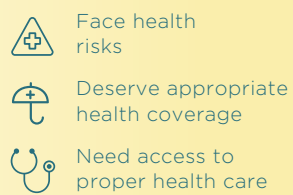

